\title{
Carnets
}

Revue électronique d'études françaises de l'APEF

Deuxième série - 19 | 2020

Petite fabrique d'interprètes

\section{Marguerite Yourcenar entre a pandemia e a alquimia}

José Guimarães

\section{(2) OpenEdition}

1 Journals

Édition électronique

URL : http://journals.openedition.org/carnets/11999

DOI : 10.4000/carnets.11999

ISSN : 1646-7698

Éditeur

APEF

Référence électronique

José Guimarães, « Marguerite Yourcenar entre a pandemia e a alquimia », Carnets [En ligne], Deuxième série - 19 | 2020, mis en ligne le 31 mai 2020, consulté le 23 décembre 2020. URL : http:// journals.openedition.org/carnets/11999; DOI : https://doi.org/10.4000/carnets.11999

Ce document a été généré automatiquement le 23 décembre 2020.

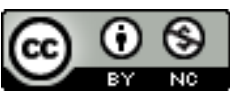

Carnets est mis à disposition selon les termes de la licence Creative Commons - Atribution - Pas d'utilisation commerciale 4.0 International. 


\title{
Marguerite Yourcenar entre a pandemia e a alquimia
}

\author{
José Guimarães
}

\section{NOTE DE L'AUTEUR}

Este texto integra, em parte, a tese de doutoramento Novas Leituras de Yourcenar : a recusa da agonia, defendida a 28 de outubro de 2019 na Universidade do Minho. Alguns dos aspetos aqui abordados foram apresentados no Colóquio 0 Imaginário Esotérico. Literatura, Cinema, Banda Desenhada, realizado na Universidade do Minho em abril de 2015.

1 Este artigo pretende contribuir para um novo olhar sobre a questão da pandemia e das alterações climáticas a partir de uma leitura de L'Euvre au noir. Atentaremos no percurso de vida de um médico e alquimista do Renascimento, Zénon Ligre, que figura as dores de crescimento - individuais e coletivas - nos planos físico e espiritual inerentes ao Homem. Atravessando uma época marcada pela guerra, pela fome e pela epidemia, Zénon ilustra a razão pela qual somos seres tão complexos e tão frágeis.

2 O caminho que Marguerite Yourcenar faz percorrer o seu herói rumo à Obra Maior de qualquer alquimista é indissociável do seu papel de médico, tratando os pobres e os mais fracos, levando o leitor, por conseguinte, a mergulhar na profundeza do ser humano, nas suas fraquezas e grandezas, e quiçá refletir sobre a sua própria essência.

Para além do papel de médico e cirurgião de Zénon, é-lhe dado a cursar um caminho místico pela sua autora dado que, para Yourcenar, esta vertente detém um papel importante na sua obra em geral e, notoriamente, no caso em apreço de L'Euvre au Noir.

4 A autora manifestou no decurso da sua vida um interesse muito particular pela espiritualidade do ser humano, bem como pela relação, a maior parte das vezes desastrosa e mortífera, deste com o meio ambiente. A correlação entre a difícil coabitação do Homem com a Terra parece propiciar fenómenos como a pandemia do século XXI, vinda do Oriente, tal como a peste bubónica, chamada Peste Negra, surgida 
no século XIV. Esta coexistência, segundo as palavras de Edward Wilson, condenou a bioesfera, no mínimo, à instabilidade : "to the grief of most preexisting life forms, came humanity". (Wilson, 1999 : 107).

5 Na opinião de Marguerite Yourcenar, somos muitos e somos demasiados ; tanto que em Sources II, no capítulo Méditations dans un jardin, na parte intitulada Souhaits, a autora de L'Euvre au Noir advoga o controlo da natalidade como forma de manter a população mundial em níveis sustentáveis declarando :

Je souhaiterais vivre dans (...) un monde où il serait honteux et illégal d'avoir plus de trois enfants. Un monde où la population du globe, par des pratiques sexuelles raisonnables, se serait ramenée et se maintiendrait au-dessous du milliard d'habitants (Yourcenar, 1999 : 239).

6 Para a escritora, sensível às políticas de sustentabilidade, existe a necessidade da oração, prática destinada à reflexão sobre os seus atos e a consequência dos mesmos. Para Yourcenar este passa a ser um dos seus temas recorrentes, sobretudo à medida que avança na idade. A sua afinidade pela espiritualidade não se enquadra numa confissão específica, mas por uma religiosidade, um misticismo que acrescente ao Homem uma vertente que o leve a alcandorar-se à verdadeira comunhão com a natureza e o universo e é em L'Euvre au Noir que Marguerite Yourcenar aprofunda mais esta matéria.

7 Zénon, personagem principal de L'Eeuvre au noir, é um médico, filósofo e alquimista, nascido em Bruges no século XVI, em plena época de grandes convulsões sociais e religiosas, "une de ces époques où la raison humaine se trouve prise dans un cercle de flammes" (Yourcenar, 2013: 178). Esta personagem é-nos apresentada desde o nascimento até ao suicídio, cometido por volta dos sessenta anos, aquando do seu encarceramento por acusação de heresia. O alquimista habita num continente de miséria, guerra e fome, assolado pela Peste Negra : a Europa da Reforma, da Inquisição e de seitas religiosas fanáticas, como, por exemplo, a Anabatista, objeto do capítulo $L a$ mort à Münster. $\mathrm{O}$ facto de este místico alquimista ser um médico, um homem de ciência constitui a possibilidade de Marguerite Yourcenar abordar os malefícios advindos do exagero dos números da população mundial, propiciando o surgimento de doenças infectocontagiosas e subsequentes fenómenos de pandemia. Deste modo, surge o episódio da peste em Basileia e Colónia, no capítulo Les Fugger de Cologne. Em Note de l'auteur, Marguerite Yourcenar refere que :

L'épisode de la peste à Bâle et à Cologne se justifie par la fréquence de ce mal presque endémique dans l'Europe du XVIe siècle, mais l'an 1549 a été choisi pour les besoins du récit et [...] à une recrudescence connue en pays rhénans (Yourcenar, 2013:505).

8 Se transpusermos a barreira do tempo, poderemos, facilmente, verificar que a conjuntura social e política da sociedade humana, na realidade, pouco se alterou. As mudanças registadas ao longo dos séculos deram-se sobretudo a nível tecnológico. No âmbito das mentalidades, a priori, a evolução não foi muito significativa. Estas tendem a ser mais retrógradas e, em situações de stress social, extremam-se com comportamentos aparentemente inaceitáveis em momentos de normalidade.

O século XVI, época retratada em L'CEuvre au Noir, é uma época adversa marcada por guerras sanguinárias, pelo poder desmesurado da Inquisição, pela cisão no seio da Igreja aquando da Contrarreforma, pelo dogmatismo e consequente repressão religiosa. 
10 Situado neste período, o percurso de vida de Zénon é uma metáfora perfeita : o caminho tortuoso, perigoso e longo da busca da Pedra Filosofal, logo da espiritualidade, da perfeição e da ascensão à comunhão com o Universo. Esta afirmação é sustentada pelas palavras de Yvette Centeno no seu volume Literatura e Alquimia. Ensaios, mais concretamente no ensaio intitulado Alquimia e Misticismo: Uma Aproximação. Centeno cita Evelyn Underhill quando este ensaísta refere que o terceiro grupo de místicos (numa classificação por si estabelecida) tem consciência do Divino como uma Vida Transcendente, imanente ao mundo e ao eu, e de uma estranha semente espiritual dentro de si, que, ao desenvolver-se, eleva o Homem a níveis superiores de caráter e consciência, levando-o a atingir o seu objetivo : “(...) Para estes, a vida mística envolve uma mudança interior, muito mais do que uma procura exterior. É precisamente com estes que se identificam os alquimistas e a sua Obra, que mais não é do que o acabamento, o aperfeiçoamento do próprio ser humano" (Centeno, 1987 :11-12).

110 médico enquadra-se no misticismo e na alquimia herméticos. Os alquimistas aqui enquadrados não visam atingir a Pedra Filosofal material ; almejam, pelo contrário, a fabricação do ouro místico, a descoberta de um Homem mais perto da deidade, ciente da sua alma e do seu espírito, em comunhão e unidade com Deus, como podemos verificar no excerto que a seguir transcrevemos :

La mayoría de los autores (...) se halla de acuerdo asimismo en distinguir dos tipos o concepciones de la alquimia : la alquimia-ciencia y la alquimia-mística (...). Para 0. Wirth, por ejemplo, la alquimia no es sino una escuela de perfeccionamiento moral, individual o colectivo. Recordando el célebre principio "nuestros metales no son los metales comunes, sino que son vivientes" afirma que el auténtico campo alquimista es el hombre y la sociedad (Jung, $1983: 11$ ).

12 Como temos vindo a asseverar, este misticismo professado por Zénon representa a busca do conhecimento que o ser humano deveria intentar, idealmente, para escapar à repetição rotineira de uma existência em que mais não deseja do que a satisfação das necessidades básicas, a submissão a um consumismo provocado por uma sociedade construída para adulterar a natureza e tornar o Homem escravo de si mesmo.

13 No início da sua caminhada, Zénon, filho bastardo, é destinado à carreira religiosa, consoante os costumes da época. 0 jovem, arisco e orgulhoso, mesmo impiedoso para com o seu semelhante, revela, contudo, uma curiosidade enorme pelo saber teórico e prático, tendo sido iniciado, nessa altura e ainda que rudimentarmente, nos conhecimentos alquímicos por Bartolomeu Campanus, seu primeiro mestre.

14 A par do saber livresco, o jovem desenvolve as suas capacidades na companhia do inventor Colas Gheel. Juntos constroem teares que acabam por se revelar um foco de problemas para os artesãos e para o abastado Henri-Juste Ligre, tio de Zénon, membro da ascendente burguesia, detentora de capitais consideráveis, da qual dependiam financeiramente os príncipes e as nações. A construção destes aparelhos ilustra a faceta perniciosa da evolução tecnológica que provocará o incremento progressivo da servidão humana e o distanciamento do mundo natural e, logicamente, o desequilíbrio da balança ecológica :

[C]es ouvriers de bois et de métal qui ne buvaient ni ne braillaient, faisaient à dix l'ouvrage de quarante, et ne profitaient pas de la cherté des vivres pour demander une augmentation de paie (...). [C]es métiers à tisser mécaniques dont les élucubrations mécaniques n'auraient finalement pour effet que d'extorquer des hommes plus de travail et d'empirer leur chômage (Yourcenar, $2013: 43-45$ ). 
Logo no início do romance, o leitor depara com um episódio indiciador do que será a vida futura do jovem aspirante a filósofo. Juntos, pela estrada que os levaria ao mundo, Zénon e seu primo, Henri-Maximilien Ligre, trocam palavras sobre os seus planos. Henri-Maximilien sonha com uma vida de armas, mulheres e glórias, enquanto Zénon parte à procura de alguém que o espera - "Hic Zeno" (Yourcenar, 2013 : 20), ou seja, ele mesmo.

Objetivos diferentes, caminhos diferentes: "Ils se séparèrent au prochain carrefour. Henri-Maximilien choisit la grande route. Zénon prit un chemin de traverse" (ibidem).

Assim, o simbolismo dos diferentes caminhos escolhidos pelos dois primos deixa antever o difícil fardo de Zénon que busca a "Luz", a superação de si próprio, o desafio das fronteiras que a sociedade e a religião impõem ao indivíduo. A opção de Zénon é reflexo do simbolismo da sua vida, podendo compreender-se melhor o alcance do caminho a percorrer através das palavras de Jung :

el auténtico camino que lleva a la totalidad está integrado por rodeos y caminos equivocados condicionados por el destino. Es una longísima vía, no un camino recto, sino una línea sinuosa que une posturas antagónicas entre sí, una línea que recuerda al caduceo de orientación, un sendero cuya sinuosidad laberíntica no carece de espanto. Es este camino donde tienen lugar las experiencias que se acostumbra a calificar de "difícilmente accesibles" (Jung, 1989 : 9-10).

Poder-se-á entender que Zénon, apesar das suas imperfeições, personifica aqueles que, de entre os seres humanos, consideram que o Homem tem de ser parte integrante da paisagem, deve respeitar a ordem ambiental e não violentar o meio que o rodeia, enquanto Henri-Maximilien personifica o conquistador, o ser humano que domina e utiliza a biosfera a seu bel-prazer. É por demais óbvio que Yourcenar veicula através de Zénon as suas opiniões ecológicas.

19 A vida do herói define-se em diversas cores, refletindo as etapas alquímicas, decorrendo num labirinto circular, qual viagem de circum-navegação humana. Começa em Bruges e termina nesta mesma cidade. Jovem, parte em busca do conhecimento e da técnica. É um intelectual que, passo a passo, vai ascendendo rumo ao conhecimento.

De início presunçoso, Zénon olha com desprezo para os que o rodeiam, como se todos fossem néscios, desmerecedores da sua compaixão ou empatia. É desprezo que sentimos perpassar nas suas palavras, quando, jovem, sentado junto à lareira, invetiva um Colas Gheel que pede clemência para o seu protegido, Thomas, condenado à forca :

Ces malheureux (...) semblaient dociles comme des moutons qu'on mène à la tonte ; ils ôtèrent leurs bonnets ; les plus humbles s'agenouillèrent.

- Grâce pour Thomas, mon compère! Grâce pour Thomas dont mes machines ont troublé la raison, psalmodiait Colas Gheel. Il est trop jeune pour pendre au gibet !

— Quoi ? - dit Zénon, Tu défends ce gueux qui a jeté bas notre ouvrage ? Ton beau

Thomas aimait danser : qu'il danse en plein ciel (Yourcenar, $2013: 59-60)$.

Esta sobranceria do jovem Zénon, transmuta-se, com os anos, num distanciamento social - no seu olhar o Outro -, que o mantém distante do seu semelhante. Mesmo na sua prática médica, Zénon não reduz a distância entre si e o Outro, mantendo-se um eremita determinado na busca de si próprio :

Peu à peu, comme un homme qui absorbe chaque jour une certaine nourriture finit par en être modifié dans sa substance, (...) des changements presque imperceptibles se faisaient en lui, fruit d'habitudes nouvelles qu'il s'était acquises. Mais la différence entre hier et aujourd'hui s'annulait dès qu'il y portait le regard: il exerçait la médecine, comme il l'avait toujours fait, et il n'importait guère que ce 
fût sur des loqueteux ou sur des princes. (...) Non habet nomen proprium : il était de ces hommes qui ne cessent pas jusqu'au bout de s'étonner d'avoir un nom, comme on s'étonne en passant devant un miroir d'avoir un visage, et que ce soit précisément ce visage-là. Son existence était clandestine et soumise à certaines contraintes : elle l'avait toujours été. Il taisait les pensées qui pour lui comptaient le plus (idem : 209-210).

No episódio de juventude que acabamos de invocar é importante notar a proximidade de Zénon ao fogo, elemento preponderante ao longo da obra, e que, na nossa opinião, poderá já ser interpretado com toda a sua simbologia.

Por um lado, o fogo é o elemento por excelência do trabalho alquímico, e, por outro, anuncia premonitoriamente o final que espera Zénon, condenado à morte na fogueira.

No romance em exegese, a importância do elemento ígneo, no sentido literal e metafórico, pode ser objeto de uma análise fenomenológica baseada na imaginação da matéria poética e das grandes categorias elementares do universo à luz do ensaio de Gaston Bachelard, filósofo do conhecimento científico, intitulado A Psicanálise do Fogo. Neste, podemos encontrar citações de autores dos séculos XVII e XVIII que lograrão dar-nos algumas pistas interpretativas acerca da vida de Zénon, da sua compleição física, bem como da sua personalidade, ajudando a compreender a sua misoginia e a sua tendência para o isolamento, características elencadas nestes excertos como comuns aos mestres alquimistas.

Para além de elemento alquímico. o fogo é um instrumento que Zénon, enquanto médico cirurgião, utiliza como meio de higienização contra a peste, como veremos mais adiante.

A personagem principal de L'Euvre au Noir passa a sua vida de lugar em lugar : não tem ligações de amizade prolongadas e, muito menos, relações amorosas, além daquelas de caráter fortuito, pautando-se nestas pela bissexualidade, notando-se mesmo, no que respeita à vida sentimental, uma tramitação constante. As únicas relações duradouras que Zénon teve foram o seu primo Henri-Maximilien, com quem se cruzava espaçadamente, Jean Myers, o seu amigo cirurgião-barbeiro de Bruges, e o Prieur des Cordeliers. Na obra, de uma forma geral, a mulher surge como elemento de instabilidade e de sedição, como semente do mal, o que poderá explicar a sua misoginia. Talvez não seja despiciendo mencionar, a título de exemplo, a mãe de Zénon, Hilzonde, que se deixou abusar por um prelado italiano de falas mansas e, mais tarde, vota o filho ao desprezo por este lhe lembrar o seu pecado lúbrico. Posteriormente casada com o velho negociante Simon Adriansen, adere à seita anabatista e, em Münster, deixa-se tomar sexualmente e de forma desbragada pelo louco que liderava a insurreição religiosa. Outra personagem feminina que sobressai, pela iniquidade e boçalidade, é a empregada de Jean Myers, Catherine, que recebe Zénon em casa e o "visita", levando-o a um encontro sexual que o deixa repugnado. $O$ elemento feminino personifica a instabilidade, a tentação, a inconstância e o pecado :

Existem "três espécies de fogo, o natural, o não natural e o contra a natureza. 0 natural é o fogo masculino (...). o fogo não natural é o fogo feminino. (...) [0] feminino [encontra-se] ligado ao fumo, [sendo] a mulher inconstante como o vento"1 (Bachelard, 1972 : 95).

27 Le « hasard ces jours-là avait pris figure de femme " (Yourcenar, $2013: 227$ ) : a boçal Catherine envenena o velho cirurgião porque, na sua pouca inteligência, supõe que Zénon fará dela sua companheira, acusando-o, mais tarde e por vingança, de assassinato. Por seu turno, Idalette, a outra personagem feminina que contribui para a 
perdição de Zénon, é a causadora da desgraça final devido às " désordres de la chair » que pratica em conjunto com um grupo de frades capuchinhos, sendo descoberta após estrangular o filho recém-nascido, fruto dos amores ilícitos da sua assembleia de " anjos ».

Podemos estabelecer um paralelismo entre a susodita citação e as personagens femininas de L'Euvre au Noir que acabamos de referir : Zénon transcorre a sua vida à procura da sua Pedra Filosofal, logo de si mesmo, sendo colocado em perigo pelo ser inconstante e disruptivo que é a mulher, Eva caída em desgraça, elemento líquido que apaga o fogo masculino :

Para se compreender bem esta sexualização dos fogos alquímicos e a valorização predominante do fogo masculino (...) não nos devemos esquecer que a alquimia é unicamente uma ciência de homens, de celibatários, de homens sem mulher, de iniciados isolados da comunicação humana em proveito de uma sociedade masculina. Esta não recebe diretamente as influências do devaneio feminino. A sua doutrina do fogo é pois muito polarizada por desejos insatisfeitos (idem : 96-97).

Reconhecemos nestas palavras de Bachelard as de Zénon e a sua dificuldade em estabelecer relações humanas, principalmente, como já referimos, com a mulher. Os poucos encontros que o médico teve com o sexo feminino, patentes nas suas próprias reflexões, foram, talvez, “[un] obscur souci d'essayer l'effet des enseignements hermétiques sur le couple parfait qui reforme en soi l'antique androgyne" (Yourcenar, $2013: 227)$.

No caminho que tem de percorrer para executar a Grande Obra, o alquimista não pode e não deve abstrair-se do fulcro da sua demanda, sob pena de a fazer perigar, já que, segundo Bachelard, "[0] fogo íntimo e masculino, objeto da meditação do homem isolado, é naturalmente o fogo mais poderoso" (Bachelard, 1972 : 97). Seguidamente, assiste-se a um círculo vicioso : Zénon não se relaciona com as outras personagens para não se enfraquecer e, ao não fazê-lo, perde a capacidade de sociabilização, restando-lhe breves encontros, sexuais, com outros seres humanos. Esses encontros são, muitas vezes, pautados pela premonição da desgraça - "le vin de la luxure tirait sa force des sucs de l'âme aussi bien que de ceux du corps" (Yourcenar, 2013: 227) - e esgotam Zénon, deixando-o amargurado.

31 Voltando ao grande desígnio da vida da personagem principal de L'Euvre au Noir, a Grande Obra iniciara-se há pouco tempo e o jovem mal lhe conhecia os contornos. Estava a preparar-se para o primeiro estádio, a tomar consciência do universo infinito de conhecimentos trazidos por uma vida ao espírito que habita num corpo. O filósofo empreendia, assim, uma dura viagem de modo a ultrapassar as grilhetas da mediocridade.

Pouco após os factos que temos vindo a elencar, Zénon deixa Bruges e a sua infância. Vai pelo mundo fora em busca do conhecimento, em busca de si próprio. Estuda teologia, medicina, alquimia. Tem, em Espanha, na pessoa de Dom Blas de Vela, prior de um convento de Jacobitas, um professor que o inicia na Cabala e lhe permite progredir nos segredos da Alquimia. Embora estando longe, chegam a Bruges vários boatos sobre o estudante :

On crut ensuite l'avoir vu à Paris, dans cette rue de la Bûcherie où les étudiants dissèquent en secret des morts, et où se prennent comme un mauvais air le pyrrhonisme et l'héresie. (...) On crut le reconnaître en Languedoc dans la personne d'un magicien séducteur de femmes, (...) en Catalogne (...) recherché pour le 
meurtre d'un jeune garçon (...). On savait vaguement qu'il s'intéressait à des spéculations sur la physiologie et l'anatomie, et l'histoire de l'enfant assassiné, qui n'était pour les grossiers ou les crédules qu'une instance de magie ou de noire débauche, devenait sur les lèvres des plus doctes celle d'une opération ayant pour but de transvaser du sang frais dans les veines d'un riche Hébreu malade (Yourcenar, 1988 : 75-76).

São-lhe atribuídos inúmeros feitos, do Ocidente ao Oriente, como se ele fosse um fantasma omnipresente. Entre vários ofícios, foi médico de empestados e o cirurgião que conspurcava "[les] mains de pus et de sang" (Yourcenar, $2013:$ 76). Qual fantasma, aparecia e desaparecia, de tempos a tempos :

Après une longue éclipse, on crut le revoir à Bâle au cours d'une épidémie de peste noire : une série de guérisons inespérées lui firent ces années-là une réputation de thaumaturge (idem : 79).

Em 1539, publicou um volume sobre o estudo do sistema circulatório e da sua relação com o funcionamento do coração, "On savait vaguement qu'il s'intéressait à des spéculations sur la physiologie et l'anatomie" (idem :76). Para além da medicina, Zénon é um cientista completo que, como sucede muitas vezes aos investigadores no decurso das suas pesquisas, não se apercebe de que as suas criações poderão vir a ser desvirtuadas, sendo utilizadas como armas de destruição: lembremos a invenção do fogo líquido a ele atribuída que ajudou a chacinar milhares. Ironia das ironias, aquele que se arriscava a contrair a peste junto dos doentes, foi pioneiro nas armas de destruição maciça.

No calcorrear de uma vida de nómada e incógnita - "Peu à peu, pourtant, Zénon cessait d'être (...) une personne, un visage, une âme, un homme vivant quelque part sur un point de la circonférence du monde ; il devenait un nom, moins qu'un nom" (idem : 79) -, ocorre uma passagem por Basileia e Colónia onde procurou aliviar o sofrimento de empestados, abandonados à sua sorte por cobardia dos que os rodeavam, fraqueza compreensível face à abrangência da praga e aos efeitos horríveis que causava nos infestados :

La peste, venue d'Orient, entra en Allemagne par la Bohême. Elle voyageait sans se presser, au bruit des cloches, comme une impératrice. Penchée sur le verre du buveur, soufflant la chandelle du savant assis parmi ses livres, servant la messe du prêtre, cachée comme une puce dans la chemise des filles de joie, la peste apportait à la vie de tous un élément d'insolente égalité, un âcre et dangereux ferment d'aventure. Le glas répandait dans l'air une insistante rumeur de fête noire: les badauds rassemblés au pied des clochers ne se lassaient pas de regarder, tout en haut, la silhouette du sonneur tantôt accroupi, tantôt suspendu, pesant de tout son poids sur son grand bourdon. Les églises ne chômaient pas, les tavernes non plus (idem : 121-122).

É na qualidade de médico, envergando "la houppelande rouge des médecins ayant accepté de soigner les pestiférés, et devant de ce fait renoncer à visiter les malades ordinaires" (idem: 126), que Zénon é chamado a consultar uma jovem, Bénédicte, atingida pela peste. À sua cabeceira encontra-se Martha - prima da paciente e a meiairmã que ele desconhecia -, aterrorizada. Neste episódio de onde se descrevem os últimos momentos de um moribundo atingido pela peste bubónica, Marguerite Yourcenar mostra Zénon agindo como um médico ciente dos procedimentos de higiene necessários ao tratamento de infetados :

Il essuya des lèvres un peu de sanie rougeâtre à l'aide d'un bout de charpie qu'il jeta dans le poêle. La cuiller et les gants dont il s'était servi prirent le même chemin. (...) Une fois sur l'escalier, il enleva le masque dont il s'était servi au chevet de la 
pestiférée, comme il était de règle (...). Je vous conseille de mettre sous vos narines un linge trempé d'esprit-de-vin (j'ai peu de confiance en vos vinaigres) et de veiller jusqu'au bout cette mourante (idem : 127-128).

\section{profendezs da sen pajen, tambern ele atingido pela doença, Zénon mergulha nas} profundezas da dor e vê o verdadeiro rosto da morte no sofrimento do seu amigo. Vive um duplo dilema : o homem vê morrer à sua frente o ser amado a quem não pode valer e o médico sabe que não dispõe de meios para valer ao paciente que se sabe condenado :

La créature au contraire redoute le retour à la substance informe... Dès le seuil, une fétidité m'avertit, et ces efforts de la bouche aspirant et revomissant l'eau que le gosier n'avale plus, et ce sang qu'éjaculent les poumons malades. Mais ce qu'on nomme âme subsistait, et les yeux de chien confiant qui ne doute point que son maître lui puisse venir en aide... Ce n'était certes pas la première fois que mes juleps s'avéraient inutiles, mais chaque mort n'avait guère été jusque-là qu'un pion perdu dans ma partie de médecin. Bien plus, à force de combattre Sa Majesté noire, il se forme d'elle à nous une sorte d'obscure complicité ; un capitaine finit ainsi par connaître et par admirer la tactique de l'ennemi. Il vient toujours un moment où nos malades s'aperçoivent que nous La connaissons trop bien pour ne pas nous résigner pour eux à l'inévitable; tandis qu'ils supplient et se débattent encore, ils lisent dans nos yeux un verdict qu'ils n'y veulent pas voir (idem : 153-154).

Passados vinte anos do seu último encontro, Zénon revê, em Innsbruck, o seu primo Henri-Maximilian. Continua amigo do fogo, segundo as palavras deste último ; acoitado numa forja alugada, perseguido pela Inquisição, procurando manter-se invisível. Conta a seu primo as suas viagens, as suas descobertas, as suas experiências, mas e principalmente, o conhecimento que já tem sobre o espírito humano, o seu engenho e o que o futuro, a seu ver, trará de bom e de nefasto à Humanidade. Quando HenriMaximilien lhe diz que o povo lhe atribui a capacidade de fazer ouro, Zénon nega-o. No entanto, afirma que isso será "[une] affaire de temps et d'outils adéquats". Para quem é feito "de la même matière que les astres", a dimensão temporal é relativizada, como se depreende da sua interrogação : "Qu'est-ce que quelques siècles ?" (idem : 149-160).

Por esta altura, Zénon encontra-se a pouco mais de dez anos do seu fim físico. Continua à procura de si próprio, em busca de respostas para as suas inúmeras questões. "SOLVE ET COAGULA" : o "opus nigrum" (idem : 237) é a labuta de toda a sua vida. Está cansado e não sabe se tem forças para continuar. Começa, então, o regresso. Inicia-se o fim do dédalo orbicular :

Pour la première fois de sa vie, il éprouvait l'étrange besoin de remettre les pieds dans la trace de ses pas, comme si son existence se mouvait le long d'une orbite préétablie, à la façon des étoiles errantes (idem : 181).

41 Esse labirinto circular é a roda do tempo : o sábio que no século XVI se sente impotente para alterar a violência do ser humano, para a qual paradoxalmente contribuiu com as suas invenções, vê-se reencarnado naquele que, nos nossos dias, se sente perplexo face às proporções do abismo no qual mergulhamos. 
42 Após alguns anos de vida imóvel em que exerce a vocação de médico no dispensário do mosteiro dos Cordeliers de Bruges, ajudando os paupérrimos, e de uma última tentativa de viagem para fugir a um destino já há muito traçado, Zénon é encarcerado por minudências que nem sequer lhe poderiam ser imputadas: "On tombe toujours dans une trappe quelconque : autant valait que ce fût celle-là" (idem : 358-359).

O cirurgião, que já duvidava poder, algum dia, atingir a Pedra Filosofal, dá-no-la a conhecer, paradoxalmente, no confinamento da sua cela, depois de meses de um julgamento perverso durante o qual não lhe são imputadas culpas verdadeiras. A permanência no cárcere é dedicada à fase final do processo alquímico. Entregue a reflexões, Zénon atinge as camadas mais profundas da sua consciência e vai vislumbrando a "luz" que sempre almejou :

$\mathrm{Na}$ alquimia, o homem, partindo embora da matéria (prima materia) é aos seus próprios e mais profundos enigmas que chega. Ao operar a transmutação dos "vis metais" em ouro é a si próprio que transforma, surgindo como homem finalmente iluminado, depois de uma longa procura. (Centeno, 1987 : 18).

Sabendo o seu destino, Zénon decide pôr fim aos seus dias terrenos. Médico e investigador, filósofo e alquimista até ao último átomo do seu corpo, sabe exatamente onde golpear as veias. Ao se ver esvair, descreve com precisão científica todos os momentos, todos os sintomas e sensações que o acompanham em cada um dos minutos finais. É nas últimas páginas de L'Æuvre au Noir que assistimos ao desvendar da Grande Obra e atravessamos as cores dos diferentes estádios necessários para o seu "fabrico".

A Pedra Filosofal é Zénon, é o ser humano consciente e predisposto a embarcar numa viagem dura, violenta, terrível, em busca de si próprio, do seu interior, do seu elo de conexão com o Universo :

Les ténèbres s'écartaient pour faire place à d'autres, abîme sur abîme, épaisseur sur épaisseur sombre. Mais ce noir différent de celui qu'on voit par les yeux frémissait de couleurs issues pour ainsi dire de ce qui était leur absence : le noir tournait au vert livide, puis au blanc pur; le blanc pâle se transmutait en or rouge sans que cessât pourtant l'originelle noirceur, tout comme les feux des astres et l'aurore boréale tressaillaient dans ce qui est quand même la nuit noire (Yourcenar, 2013 : 442-443).

E foi através desse ouro puro, desse "globe écarlate" (idem : 443), desse oxímoro - "jour aveuglant qui était en même temps la nuit" (ibidem) - que Zénon partiu para a "união consciente com um Absoluto vivo" (Centeno, $1987: 11)^{2}$.

O barulho agudíssimo da porta que se abria (Yourcenar, 2013: 443) é, finalmente, parafraseando Zozimo de Panópolis citado por Centeno, Zénon transformado em espírito depois de ter deixado o seu corpo, já inútil, para trás (Centeno, $1987: 16$ ) :

[T]oute angoisse avait cessé : il était libre; cet homme qui venait à lui ne pouvait être qu'un ami. Il fit ou crut faire un effort pour se lever, sans bien savoir s'il était secouru ou si au contraire il portait secours. Le grincement des clefs tournées et des verrous repoussés ne fut plus pour lui qu'un bruit suraigu de porte qui s'ouvre. Et c'est aussi loin qu'on peut aller dans la fin de Zénon (Yourcenar, $2013: 443$ ).

A propósito da frase final de L'Euvre au Noir, Marguerite Yourcenar refere a Mathieu Galley em Les Yeux Ouverts que "C'est une porte qui s'ouvre, mais nous ne savons pas sur quoi. Peut-être sur un monde où Zénon ne serait plus nécessairement Zénon, et il ne se souviendrait même plus - ou du moins plus longtemps - de l'avoir été. Un retour à l'universel. Disons plutôt un passage, qui n'est pas facile" (Galley, 1980 : 188). 

mensagem de esperança : esperança drástica, difícil e amarga, dolorosa e quase titânica que importa cumprir - sobretudo nos momentos de dúvida, de confinamento e temor para que o ser humano se consiga reinventar :

As we wait in quarantine and under lock down, we should join together (...) to ask ourselves what kind of future we can make together when we emerge (Strub, 2020). L'Euvre au noir é uma peça essencial para o conhecimento mais profundo de Marguerite Yourcenar, em particular, e do ser humano, em geral. Através de Zénon, o leitor tem acesso às fraquezas e à força de um homem que carreia em si mesmo o DNA da Humanidade. Hoje, como em 1968, revela-se importante revisitar a autora pela sua atualidade e incontestável qualidade.

\section{BIBLIOGRAPHIE}

BACHELARD, Gaston (1972). A Psicanálise do Fogo. Lisboa : Estúdios Cor.

CENTENO, Yvette (1987). Literatura e Alquimia. Lisboa : Presença.

CHEHAB, May (2007). Discursos y Conferencias. In Padilla, A. \& Torres (Orgs.), Marguerite Yourcenar y

La Ecología Un Combate Ideológico y Político. Bogotá : Ediciones Uniandes.

GALLEY, Mathieu (1980). (Ed.) Marguerite Yourcenar. Les yeux ouverts. Entretiens avec Mathieu Galley.

Paris : Centurion.

JUNG, Carl (1983). La Psicologia de la Transferencia. Barcelona : Paidós.

JUNG, Carl (1989). Psicología y Alquimia. Barcelona : Plaza \& Janes Editores.

STRUB, Spencer (2020). Illness \& Crisis, from Medieval Plague Tracts to Covid-19, The New York Review of Books|Daily, disponível em https://www.nybooks.com/daily/2020/03/25/illness-and-crisisfrom-medieval-plague-tracts-to-covid-19/ [Acedido em 14-04-2020].

WILSON, Edouard (1999). Consilience: The Unity of Knowledge. New York: First Vintage Books Random House.

YOURCENAR, Marguerite (1997). Lettres à ses amis et quelques autres. Paris : Gallimard.

YOURCENAR, Marguerite (1999). Sources II. Texte établi et annoté par Élyane Dezon Jones, présenté par Michèle Sarde. Paris : Gallimard.

YOURCENAR, Marguerite (2013). L'EEuvre au Noir. Paris : Gallimard.

\section{NOTES}

1. Nesta citação Gaston Bachelard transcreve um autor anónimo do século XVII (Bachelard, 1972 : 95-96).

2. Underhill, E. Mysticism. Londres, Methuen and Co. Ltd., apud Centeno, Y. (1987). Literatura e Alquimia. Lisboa, Presença, p. 11. 


\section{RÉSUMÉS}

O fascínio pela espiritualidade humana norteou Marguerite Yourcenar na incessante procura das profundezas da alma e no desejo de uma ascese que permitirá ao Homem ascender a níveis de conhecimento e comunhão com os elementos, inacessíveis aos displicentes. É através da alquimia, ligada ao transcendente e do exercício da medicina, ligada ao imanente humano que o seu herói Zénon dá um testemunho direto, ao leitor de L'Euvre au Noir, do caminho penoso, atribulado e perigoso que é a pedra de toque na elevação da Humanidade à comunhão com o Universo. É desta jornada feita de um misto de transcendente e de imanente que dá conta este estudo.

The fascination with human spirituality guided Marguerite Yourcenar in the incessant search for the depths of the soul and in the desire for an asceticism that will allow man to rise to levels of knowledge and communion with the elements, inaccessible to those who lack self-reflexion. It is through alchemy, linked to the transcendent and the practice of medicine, connected to the human immanent that his hero Zénon gives a direct testimony, to the reader of L'CEuvre au Noir, of the painful, troubled and dangerous path that is the touchstone in the elevation of Humanity to a communion with the Universe. This journey made up of a mixture of transcendent and immanent is the object of this study.

\section{INDEX}

Palavras-chave : Yourcenar (Marguerite), littérature française du XXe siècle, século XVI, alquimia, peste, epidemia, fogo

Keywords : Yourcenar (Marguerite), 20th century French literature, 16th century, alchemy, epidemic, fire

\section{AUTEUR \\ JOSÉ GUIMARÃES}

jmcmguimaraes[at]gmail.com 